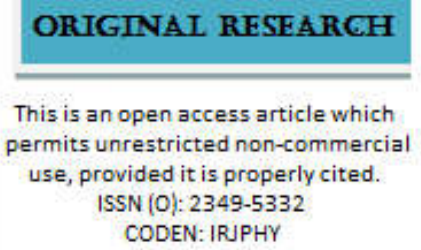

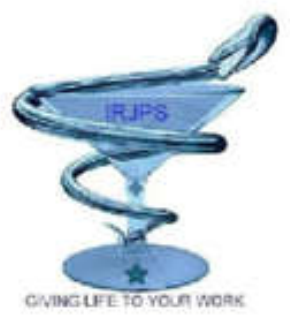

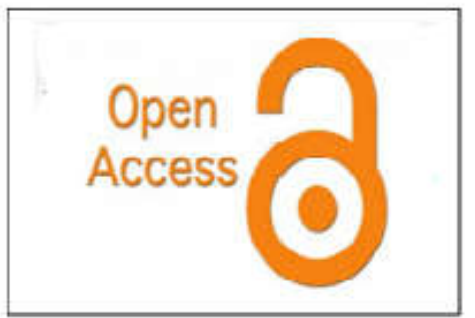

\title{
ESTIMATION AND VALIDATION OF RESIDUAL SOLVENTS IN MARKETED FORMULATION OF ANTI-HYPERTENSIVE DRUG BY GAS CHROMATOGRAPHIC METHOD
}

\author{
Pragati S. Dubey*1, Neelam Mittal ${ }^{2}$
}

Faculty of dental science, Institute of Medical Sciences, Banaras Hindu University, Varanasi

\begin{abstract}
The estimation of residual solvents by using gas chromatography (GC) with Flame Ionization Detector (FID) is monitored. The overall methods were developed by using Capillary column with dimension of $30 \mathrm{~m}$ in length, and diameter of $3.0 \mu \mathrm{m}$ with $6 \%$ cyanoprophenylmethyl/ $94 \%$ diphenylsiloxane polymer as a stationary material. Volume of $1 \mathrm{ml}$ of standard and samples was injected into the capillary column in gas chromatograph fitted with a flame ionization detector. Nitrogen gas was used as used as carrier gas. The chromatographic condition set were $150{ }^{\circ} \mathrm{C}$, column temperature initial were $40^{\circ} \mathrm{C}$ for 4 minutes, then increasing by $10^{\circ} \mathrm{C} / \mathrm{min}$ upto $160^{\circ} \mathrm{C}$ for 9 minutes, detector's temperature $290{ }^{\circ} \mathrm{C}$, with flow rate of $4.51 \mathrm{ml}$. / min. The separation of all compounds was done in 55 minutes. In marketed formulation i.e. Beniflo, Beniduce and Benihyp, we have estimated that the level of residual solvent were present within limit i.e. Methanol $<3000 \mathrm{ppm}$, IPA (Isopropyl Alcohol) $<1500$ ppm, MDC (Methylene Dichlloride) $<600$ ppm and Toluene $<180 \mathrm{ppm}$. From this all studies it was stated that, our marketed formulations are safest for our use. The method was validated according to the ICH guidelines parameters such as linearity, LOD \& LOQ, precision, accuracy, ruggedness and robustness and showed excellent results.
\end{abstract}

KEYWORDS: Headspace chromatography, Benidipine Hcl, Residual solvents, Validation.

Corresponding Authors: Pragati S. Dubey E-mail: ruchidubey008@gmail.com Contact no: $+91-8866636569$
Indian Research Journal of Pharmacy and Science; 25(2020)2194-2203; Journal Home Page: https://www.irjps.in DOI: 10.21276/irjps.2020.7.2.12 


\section{INTRODUCTION}

Quality assurance is a branch of pharmaceutical chemistry involved with analysis of chemical substance to assure their quality. It gives both qualitative and quantitative information about the composition of the substances. Qualitative technique is used to identify substances and quantitative for determination of concentration or amount of substances. Pharmaceutical analysis deals with Qualitative and Quantitative analysis of drugs in bulk, dosage forms, and in biological samples. Qualitative analysis yields information about the identity of molecule or atomic species or functional group in the sample. ${ }^{1}$ whereas quantitative analysis determines the exact amount of analytic molecules present in the sample. Gas chromatography is specifically gas-liquid chromatography which involves a sample being vaporized and injected onto the head of the chromatographic column. The sample is transported through the column by the flow of inert, gaseous mobile phase. The column itself contains a liquid stationary phase which is adsorbed onto the surface of an inert solid. Gas chromatographic technique is used for estimation of residual solvents.

Most of the solvents used in formulations have low boiling points $\left(<200^{\circ} \mathrm{C}\right)$, So that they can easily be volatilized and separated by using proper chromatographic and instrumentation conditions. During synthesis of drug substances, Excipient, or during the product formulation organic solvents are applied in daily routine in Pharmaceutical Industry. Due to their toxicity, they are harmful for the patients, like their odor, taste, quantity of crystal in drug substances There are various techniques or methods available to remove them (e.g. under high temperature and/or low pressure). But even after these techniques or methods, some small amount of organic solvents still remains there in drug substances. These small amount or quantities of organic solvents are referred as Residual solvents (RS) or Organic volatile impurities (OVs) or Carcinogenic residual solvents (CRS) ${ }^{2}$. In late 70 's, the test and control for residual solvent (RS) in Pharmaceutical product/substance was perceived. In some monograph of U.S. Pharmacopoeia and Great Britain Pharmacopoeia (80+ add 82), these tests were added. The main test like OVI test $<467>$ in USP was applied to control the use of residual solvent (RS) in Pharmaceutical product. This test was performed to check the acceptable limits of Benzene, Chloroform, Dichloroethylene, Trichloroethylene, and 1-4 Dioxane. After that the International Conference of Harmonization (ICH) of "Technical Requirement for registration of Pharmaceutical for Human Use" was situated in early 80 's. Then types and categories of Impurities or Residual solvents (RS) were recognized in paper and Journals ${ }^{3,4}$. In ICH guidelines, which are set up by European, Japan and USA for registration of Pharmaceutical product under Topic $\mathrm{Q}_{3} \mathrm{C}$ (published in December 1997), showed "testing to be performed for residual solvents when production and purification process results in presence of such solvents". These Guidelines stated criteria for Identification and Quantification for presence of residual solvents (RS) in Pharmaceutical products with their acceptable concentration limits ${ }^{5,6}$. The $\mathrm{ICH} \mathrm{Q}_{3} \mathrm{C}$ guideline has finally approved by USP and has amended its general method to repeat it. In new general method $\mathrm{Q}_{3} \mathrm{C}$ showed shows the description of analytical method for performing the Residual Solvents (RS) testing. Finally, testing and control limit concentration for determination of $\mathrm{RS}$ is stated in USP, EU, JP guidelines ${ }^{7,8}$. Headspace chromatography is widely used nowadays for 
estimation of residual solvents, where solid or liquid sample placed in closed vessel to reach equilibrium between sample and gas volume. HS techniques given by many authors as (Masoom Raza Siddiqui, et. al., 2017; Anumolu PD, et. al., 2016; Xiao - Zhen Feng, et. al., 2015; Saurabh Pandey, et. al., 2011; Abhisekh Gupta, et. al., 2010; Prasanna Reddy. Battu, et. al., 2009; Karine Jacq, et. al., 2008; Broussard LA, et, al., 2001.)

Benidipine hcl, a dihydropyridine calcium channel antagonist, decreases body weight and also has hypotensive effect. It presents a very long lasting activity that can be explained by its high affinity for cell membrane from dihydro protein (DHP) binding site, the additional property of Benidipine is vascular selectivity towards peripheral blood vessel. The mechanism of its inhibitory effect on body weight is unclear, although this agent increases blood flow in brown adipose tissue, which functions as a main thermo genic organ. Used for patient with high blood pressure and angina pectoris disease. The IUPAC name is 1,4 Dihydro - 2, 6 - dimethyl-4- (3- nitrophyl)-3, 5pyridine dicarboxylic acid methyl 1(phenylmethyl)-3- piperidinyl ester, white powder, heat sensitive. Molecular formula is $\mathrm{C}_{28} \mathrm{H}_{32} \mathrm{ClN}_{3} \mathrm{O}_{6}$ and melting point is 540- $543{ }^{\circ} \mathrm{C}$.

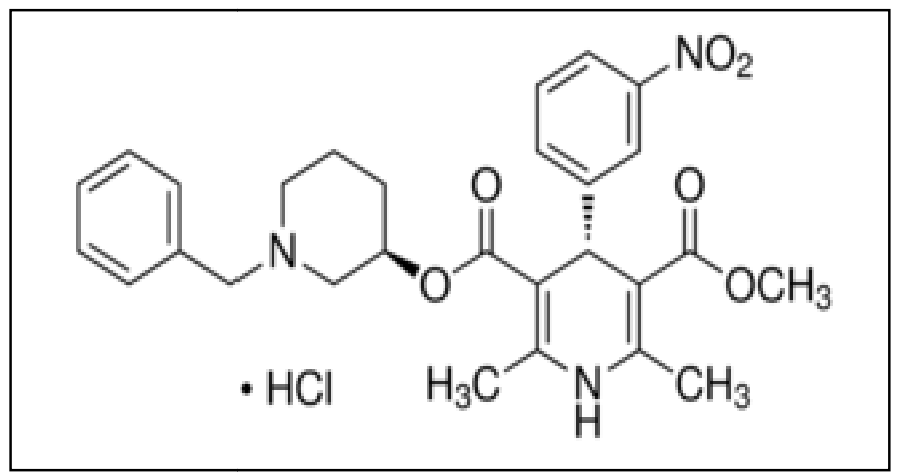

Figure 1: Structural diagram of Benidipine $\mathrm{Hcl}$

\section{INSTRUMENTS AND CHEMICALS}

Gas chromatography system: The GC system2014 with Software GC solution 2.14 was used in development and validation of GC method. FID (Flame ionization detector) was used as a Detection system. Separation was achieved by using Capillary column with dimension of $30 \mathrm{~m}$ in length, and diameter of $3.0 \mu \mathrm{m}$ with $6 \%$ cyanoprophenyl/ 94\% dimethyl polysiloxane polymer (SH-Rtx ${ }^{\mathrm{TM}}$ - 624) or BP-624. Stationary material was made up of silica. The column used was Capillary, carrier gas was nitrogen, and Detector used was FID and the data were collected through software GC solution 2.14.
Chemicals: Used marketed formulations of Benidipine $\mathrm{Hcl}$ were bought from pharmacy in Gujarat, India. Details of Marketed formulation are BENIHYP 4 mg (Manufactured by: J. B. CHEMICALS Pvt. Ltd.).

\section{EXPERIMENTAL WORK}

i. Selection of solvent (Diluent): The solubility of our sample (i.e. Benidipine $\mathrm{Hcl}$ ) was carried out by using different solvents like Water, DMF (dimethyl formamide), and DMSO (dimethyl siloxane). In which, weighed an accurate 
amount of Benidipine $\mathrm{Hcl}(0.5 \mathrm{gm})$ and dissolved it in $(10 \mathrm{ml})$ of different solvents like Water, DMF and DMSO respectively. The solution of drug in the solvent was kept in sonicator for $15 \mathrm{~min}$ to dissolve the drug. Then Pipetted out $5 \mathrm{ml}$ in HS vial and the result was obtained by taking chromatographic peak to check the compatibility of the solvents with the drug samples.

ii. Chromatographic conditions: A volume of $1 \mathrm{ml}$ of standard and samples was injected into the capillary column in gas chromatograph fitted with a flame ionization detector. Nitrogen gas was used as carrier gas. The chromatographic condition set were $150{ }^{\circ} \mathrm{C}$ at a split ratio of 1:3. The pressure was maintained at 21.3 psi with flow of $4.51 \mathrm{ml} / \mathrm{min}$. the temperature of detector was set at $290{ }^{\circ} \mathrm{C}$. Temperature gradient was maintained at $40{ }^{\circ} \mathrm{C}$ for four min and then increased at a rate of $10{ }^{\circ} \mathrm{C} / \mathrm{min}$ upto a final temperature of $160^{\circ} \mathrm{C}$ and maintained for $9 \mathrm{~min}$.

iii. Head Space Conditions: In headspace conditions, the GC cycle time was kept for 35 minutes, injection speed was maintained as $15 \mathrm{ml} / \mathrm{min}$ with injection volume of $1 \mathrm{ml}$. Headspace vial volume was $20 \mathrm{ml}$ in which $5 \mathrm{ml}$ sample was filled for detection of residual solvents. Syringe filling speed was about $25 \mathrm{ml} / \mathrm{min}$ with three times of rinse. Equilibrium was maintained for 39 minutes with temperature $105^{\circ} \mathrm{C}$.

Table 1: Gas chromatographic condition

\begin{tabular}{|c|c|}
\hline COLUMN & CAPILLARY COLUMN \\
\hline Stationary phase & $\begin{array}{l}\text { 6\% cyanoprophenyl/ } 94 \% \text { dimethyl polysiloxane polymer } \\
\text { (BP-624). }\end{array}$ \\
\hline Carrier gas & Nitrogen \\
\hline Detector & FID \\
\hline Injection Temperature & $150^{\circ} \mathrm{C}$ \\
\hline Detector Temperature & $290^{\circ} \mathrm{C}$ \\
\hline Inlet pressure & $21.3 \mathrm{psi}$ \\
\hline Software & GC Solution 2.41 \\
\hline Data system & AOC 5000 \\
\hline Injection Volume & $1 \mathrm{ml}$ \\
\hline Injection mode & Split 1:3 \\
\hline Flow control mode & Linear velocity $(4.51 \mathrm{ml} / \mathrm{min})$ \\
\hline Oven temperature program & $\begin{array}{c}\text { Initial } 40^{\circ} \mathrm{C} \text {, for } 4 \text { minutes } \\
\text { Increase } @ 10^{\circ} \mathrm{C} \text { per minute upto } 160^{\circ} \mathrm{C}\end{array}$ \\
\hline
\end{tabular}




\section{QUANTIFICATION OF RESIDUAL SOLVENTS:}

\section{Standard Stock Solution (A)}

Methanol Stock solution-I: Accurately transferred $0.380 \mathrm{ml}$ Methanol (equivalent to $3000 \mu \mathrm{g} / \mathrm{ml}$ ) into a $100 \mathrm{ml}$ volumetric flask containing about $70 \mathrm{ml}$ of DMSO to the flask and diluted up to the mark with same solvent

Isopropyl Alcohol Stock Solution-II: Accurately transferred $0.555 \mathrm{ml}$ Isopropyl Alcohol (equivalent to $5000 \mu \mathrm{g} / \mathrm{ml}$ ) into a $100 \mathrm{ml}$ volumetric flask containing about $70 \mathrm{ml}$ of DMSO to the flask and diluted up to the mark with same solvent.

Toluene Stock Solution-III: Accurately transferred $0.910 \mathrm{ml}$ Toluene (equivalent to $890 \mu \mathrm{g} / \mathrm{ml}$ ) into a $100 \mathrm{ml}$ volumetric flask containing about $70 \mathrm{ml}$ of DMSO to the flask and diluted up to the mark with same solvent.

MDC Stock solution-IV: Accurately transferred $0.58 \mathrm{ml} \mathrm{MDC} \mathrm{(equivalent} \mathrm{to} 600 \mu \mathrm{g} / \mathrm{ml}$ ) into a 100 $\mathrm{ml}$ volumetric flask containing about $70 \mathrm{ml}$ of DMSO to the flask and diluted up to the mark with same solvent. Standard stock solution preparation A

Individual Standard Solutions (B): Pipetted out $20.0 \mathrm{ml}$ of stock solution-I, stock solution-II, stock solution-III and stock solution-IV into an individual $100 \mathrm{ml}$ volumetric flask respectively and diluted up to the mark with DMSO. Pipetted out $5 \mathrm{ml}$ of each solution into individual HS vial and sealed the vials.

Mix Standard Solution (C): Pipetted out of $20.0 \mathrm{ml}$ of stock solution-I, stock solution-II, stock solution-III and stock solution-IV and diluted up to the mark with DMSO. Pipetted out $5.0 \mathrm{ml}$ of this solution into a HS vial and sealed the vial.

Diluent / Blank Solution: Pipetted out $5.0 \mathrm{ml}$ DMSO into a HS vial and seal the vial with PTFE silicon septa closure and secured the closure with aluminum cap.

\section{METHOD VALIDATION}

The method was validated according to the $\mathrm{ICH}$ guidelines parameters such as linearity, LOD \& LOQ, precision, accuracy, ruggedness and robustness. The results were obtained within limit of acceptance criteria as follows:

i. System suitability criteria were fulfilled.

ii. Co-relation coefficient $\left(\mathrm{r}^{2}\right)$ was found to be more than 0.990

iii. The \% RSD of the peak area of replicate injections was found to be less than 15 $\%$.

iv. The $\%$ recovery at each level was found to be within limit of $90 \%-110 \%$

\section{RESULTS AND DISCUSSION}

1) Quantification of residual solvent in formulation:

Table 2: Quantification of residual solvent in Benidipine Hcl

\begin{tabular}{|c|c|c|c|}
\hline Peak & Name & Retention Time & Area \\
\hline 1 & Methanol & 2.178 & 42160 \\
\hline 2 & IPA & 4.185 & 16153 \\
\hline 3 & MDC & 4.985 & 256548 \\
\hline 4 & Toluene & 10.967 & 15556 \\
\hline
\end{tabular}




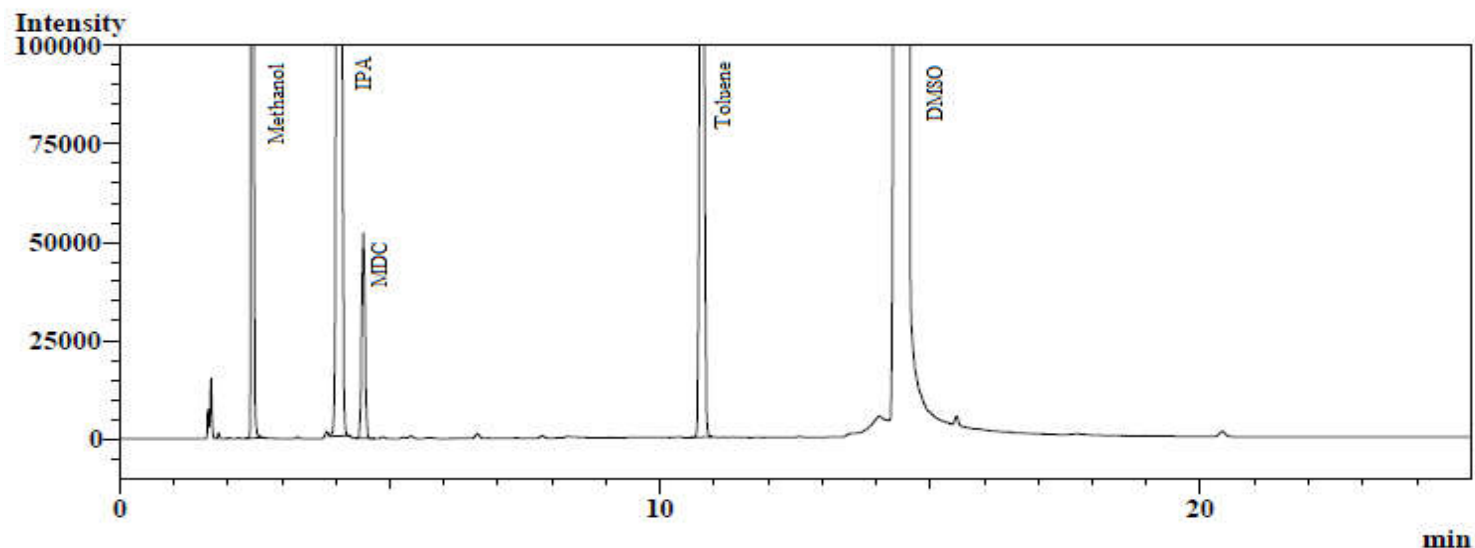

Fig.2: Chromatogram of residual solvent in Benidipine Hcl

Discussion: From the chromatogram of sample/formulation, the concentration limit of sample within limit is checked by emplacing the area of the solvents in linearity equation $(y=$ $\mathrm{mx}+\mathrm{c})$, the concentration of Methanol, IPA, MDC and Toluene were obtained as 466.23, 24.29, 27.81 and $9.198 \mathrm{ppm}$ respectively. The concentrations of solvents were found within limit as per guidelines.

2) Linearity: Different ranges of standard solutions were prepared by diluting out known volume of intermediate stock solutions, having concentration of given diluents in the respective tables, were made separately from $50.0 \%$ concentration to 150 $\%$ concentration of limit. Each of the solution was analyzed as per proposed method and the chromatograms were obtained. The results obtained were statistically evaluated for Correlation of coefficient $\left(\mathrm{r}^{2}\right)$, Standard error of estimate and $\mathrm{y}$ intercept.

\section{3) Precision:}

- Inter-day precision: The system precision was checked by using standard substance to ensure that the analytical system was working properly. Six replicate injections of standard solutions were injected in different timing to analyze the system as per the proposed method and the chromatograms obtained. The \%RSD of standard solvents and area were calculated.

- Intra-day precision: To demonstrate the method precision when method is executed by a different analyst and on different day and the results obtained will be compared. The precision of analytical method was the degree of agreement among individual test results when the method was applied repeatedly to multiple samplings of homogeneous samples. It provided an indication of random error results and was expressed as coefficient of variation (CV). This was performed to indicate whether the method was giving consistent results for a single batch. Method precision was carried out by analyzing six replicate injections of standard and sample for couple of days to calculate the \%RSD and area of the solvents.

4) Limit of Detection \& Limit of Quantification: The limit of detection and limit of quantification were calculated on the basis of standard deviation and slope obtained from chromatogram of linearity solutions. The samples with known low concentration were prepared with blank. Each of 
samples was established by the minimum concentration at which the analytes were reliably quantified. Five samples of lowest concentration of Methanol, IPA, Toluene and MDC with blank DMSO were taken and standard deviation and slope were obtained to quantify the limits. By using equations, the estimation of Quantitation limits were samples reliably detected as per guidelines. The equations were taken as:

$\mathrm{LOQ}=3.3 * \mathrm{SD} / \mathrm{Slope}, \mathrm{LOD}=10 * \mathrm{SD} /$ Slope.

\section{5) Accuracy:}

Accuracy of the method was ascertained by standard addition method at 3 levels. Standard solution quantity equivalent to $50 \%, 100 \%$ and $150 \%$ were added in Samples. The amount recovered by the method was compared to the amount added. Percent deviation was calculated at each levels and a grand average across all the levels was also calculated and found within limit 90$110 \%$.
6) Robustness: The robustness of an analytical method was carried out to confirm that the method remained unaffected by small but deliberate variations in method parameters and provides an indication of its reliability during normal usage. The measurements of variations in analytical conditions were suitably controlled or precautionary statements were included in the procedure. The typical variation we were measured at different flow rate, different incubation temperature and found within acceptance criteria.

7) Ruggedness: The ruggedness was established by determining residual solvents using the same chromatographic system and the same column by two analysts on a different day. The assay result indicated that the method was capable with high precision. Additionally, good separations were achieved, which suggested that the method was selective for all components under the test and found within limit.

Table 3: Overall validation results for residual solvent

\begin{tabular}{|c|c|c|c|c|c|c|}
\hline \multirow{2}{*}{ Solvent } & Specificity & \multicolumn{3}{|c|}{ Linearity } & LOD (ppm) & LOQ (ppm) \\
\cline { 2 - 6 } & RT (min) & Slope & Intercept & $\begin{array}{c}\text { Correlation } \\
\left(\mathbf{r}^{2}\right)\end{array}$ & 0.9919 & 20.98 \\
\hline Methanol & 2.746 & 1017.4 & 516506 & 0.9963 & 4.20 & 12.73 \\
\hline MDC & 4.185 & 8506.8 & 19910 & 1 & 20.07 & 60.82 \\
\hline IPA & 10.815 & 452.15 & 3688.1 & & 33.28 & 100.85 \\
\hline
\end{tabular}

Table 4: Accuracy data for residual solvents in formulation

\begin{tabular}{|c|c|c|c|c|}
\hline Recovery level (\%) & Methanol & MDC & IPA & Toluene \\
\hline $\mathbf{5 0} \%$ & 100.09 & 100.56 & 100.41 & 100.56 \\
\hline $\mathbf{1 0 0} \%$ & 99.57 & 98.64 & 100.23 & 101.21 \\
\hline $\mathbf{1 5 0} \%$ & 101.17 & 101.65 & 100.63 & 101.65 \\
\hline Mean & 100.276 & 100.283 & 100.42 & 0.54 \\
\hline \%RSD & 0.768 & 1.520 & 0.352 & 1.14 \\
\hline
\end{tabular}


Table 5: Interday precision results

\begin{tabular}{|c|c|c|c|c|}
\hline Parameters & Methanol & MDC & IPA & Toluene \\
\hline Mean (ppm) & 3173653 & 5813611 & 2715811 & 1948 \\
\hline SD & 3219 & 7001 & 0.118 & 0.84 \\
\hline
\end{tabular}

Table 6: Intraday precision results

\begin{tabular}{|c|c|c|c|c|}
\hline Parameters & Methanol & MDC & IPA & 1056424 \\
\hline Mean (ppm) & 2546346 & 4120475 & 2266990 & 636 \\
\hline SD & 1086 & 297 & 0.102 & 0.23 \\
\hline
\end{tabular}

\section{CONCLUSION}

The study represented a simple and validated gas chromatographic method for the estimation of residual solvents content in marketed formulations. DMSO was selected as blank solvent and has no interference with samples and standard peaks. By trying various set of temperature programming for the column oven temperature, the best suited parameters for desired analysis were sorted and optimized. The developed method was found to be specific, accurate, precise and rugged. The amounts of relative substances in the marketed formulations to be well within the accepted label claim. The amounts of residual solvents present in marketed formulations were found to be within the $\mathrm{ICH}$ limits. This method is very specific as the individual peaks of residual solvents were well separated on capillary column with a chromatographic time of $4.51 \mathrm{ml} / \mathrm{min}$ and mobile phase of nitrogen. This method was validated linearity, LOD \& LOQ, precision, accuracy, ruggedness and robustness. Hence, according to the acceptance limit given in ICH guidelines, the system was validated successfully and it could be useful for the routine analysis of relative substances without interference of each other in all formulations.

\section{REFERENCES}

1. B'Hymer, Clayton., Residual Solvent Testing: A Review of Gas-Chromatographic and Alternative Techniques. Pharmaceutical Research, Volume no. 20, Issue 03, March 2003, page no. 337-44. https://doi.org/10.1023/A:1022693516409.

2. K. Grodowska and Andrzej, Analytical Methods for Residual Solvents Determination in Pharmaceutical Products. Acta Poloniae Pharmaceutica- Drug Research; Poland, Volume 67, Issue 2, June 2010, page no.030060.

3. T. A. Berger, Instrumentation and Application of Gas Chromatography, edition 01, GC Chromatographia, 1996, Page no. 63-71.

4. S. M. Khopkar, Basic concept of analytical chemistry, Tunbridge Wells: New Academic Science, edition 07, New Age International Ltd. Publisher, New Delhi, Page no. 1998.

5. D. A. Skoog; F. J. Holler; S. R. Crouch, Principle of Instrumenntal Anlaysis, edition 06, Thomson Publication, India, 2007, Page no 11039.

6. A. H. Beckett; J. B. Stenlake, Pratical Pharmaceutical Chemistry, $4^{\text {th }}$ edition., CBS Publisher and Distributors, New Delhi, Part-2, 
2002, Page no. 85-157.

7. Horracio Pappa, Organic volatile impurities, XXXI US pharmacopoeia, Forum $<467>$ General chapters 05, Volume 31, edition 06, Page no. 1435 http://www.pharmacopeia.cn/v29240/usp29nf2 4s0_c467.html.

8. J. Solanki, M. Mehta, S. Satija, and M. Garg, Regulatory and Analytical Aspects of Residual Solvents in ayurvedic formulation-A Recent Update, International Journal of research and reviews, Volume 36, $2^{\text {nd }}$ edition, April 2012, Page no. 938-949.

9. M. Kapil; S. lata, Residual solvents and various effective gas chromatographic techniques in the analysis of residual solvent, International journal of Pharma research and review, 2013, page no. 25-40.

10. Kolb B., Pospisil P., Handbook of Chromatographia, An International Journal of Separation Science, Volume 10, edition 2, 1997, Page no-705.

11. Wypych G. Ed., Handbook of residual solvents, Chemtec Publishing, Toronto Newyork, Volume 02, $1^{\text {st }}$ edition, 2001, Page. 1133.

12. Masoom Raza Siddiqui, and Raj Kumar Singh: Determination of residual solvents in Docetaxel by headspace gas chromatography, Arabian Journal of Chemistry, Volume 10, Supplement 2, May 2017, Page no. S2479. S2484.

13. Gurdeep Chatwal and Sham Anand, Textbook of analysis: Instrumental Method of Chemical Analysis, Himalaya Publishing House, Volume 05, edition 02, 1994, Page no. 615.

14. S. B. Puranik and G. K. Rao, Determination of Residual Solvents in Bulk Pharmaceuticals by Thermal Desorption/Gas Chromatography /Mass Spectrometry, Volume 17, edition 04,
2007, Page no. 352-359.

15. G. A. Eiceman. Instrumentation of Gas Chromatography New Mexico State University, Las Cruces, USA., Volume 35, supplement 02, 2001, Page no. 1-9.

16. Shrivastava Alankar, A Review On Peppermint Oil' Asian Journal Of Pharmaceutical And Clinical Research, Volume 2, Issue 2, 2009, Page no. 27-33

17. Anumolu PD, Krishna VL, Rajesh CH, Alekya V, Priyanka B, Gas Chromatographic Assessment of Residual Solvents Present in Excipient-Benzyl Alcohol., Journal of Chromatographic Separation Technique, Volume 10, Issue 03 April (2016), Page no $7: 321$

18. Xiao - Zhen Feng, Guo- Cheng Hen, Determination of residual solvents by using headspace chromatography, Journal of Chromatographic Science, Volume 05, edition 01, 2015, Page no. 487-491.

19. P. S. Selvan and E. S. Priya, Determination of Ethanol Content in Ayurvedic Formulation Kumaryasava and Mustakarista by Gas Chromatography, Volume 28, Issue 04, 2002, Page no. 125-12.

20. Saurabh Pandey and Preeti Pandey, Residual solvents determination by Headspace gas chromatography with FID in Omeprazole API, Brazilian Journal of Pharmaceutical Science, Volume 47, Issue no.2, 2011, Page no. 64-68. http://dx.doi.org/10.1590/S198482502011000200019

21. A. J. P. Martin and R. L. M. Synge, Biochem. Instrumentation and application of gas chromatography, Biochemical Journal, Volume 02, edition 01, 1941, Page no. 1358-1368.

22. Katakam Prakash, Karanam R. Sireesha., Liquid Chromatigraphic Method For Simultaneous Determination Of Lomefloxacin 
Hydrochloride And Dexamethasone Sodium Phosphate In Eye Drops. Asian Journal of Pharmaceutical and Clinical Research, Volume 5, Issue 1, 2012, Page no. 7982.

23. Raghani A.R., High speed gas chromatographic analysis of solvents in pharmaceutical using solid phase micro extraction. Journal of Pharmaceutical Biomedical Analysis. Vol. 29, 2002, Page no. $507-518$

24. ICH, Q2 (R1), Validation of analytical procedures text and methodology, Geneva, Version 04, Nov. 2005, Page no. 1- 13.

25. S. Sohan, Chtlange, K Bargi and DM Sarkarar, Estimation of Relative substances in Pharmaceutical Products by Gas Chromatographic Method. Asian. J. Research in Chemistry, Volume 2, edition (1), March2009, Page no. 30-33.

26. Gupta H, Abhisekh, Sundaram A and Kaushik M, Development and Validation of a Headspace Gas Chromatographic Method for the Determination of Residual Solvents in Arterolane (RBx11160) Maleate Bulk Drug. Journal of Pharmacy and Bioallied Sciences 2.1 (2010):/ P. no: 32-37

27. Prasanna Reddy. Battu and M.S Reddy, Residual Solvents Determination by HS-GC with Flame Ionization Detector in Omeprazole Pharmaceutical Formulation, International
Journal of PharmTech Research, Volume 1, no.2, 2009, Page no. 230-234. http://dx.doi.org/10.1590/S1984-

825020092100324

28. Karine Jacq, Frank David, Generic method for Analysis of Residual Solvents in Pharmaceutical using Static Headspace chromatography, Research Institute for Chromatography, Jourmal of Pharmaceutical and Biomedical, Volume 48, Issue 05, 2018, Page no. 2-12.

29. Broussard LA, Pitman T, Analysis of Ethanol by using Headspace chromatographic method, Journal of the American Society for Medical Technology, volume 14, Issue 01, 2011, Page no $31-35$

30. Kumaraswamy D., Stephenrathinaraj B., Process Validation of Analytical Method Development and Validation for Omeprazole Capsules and Blend. Journal of Chromatographic analysis, Volume 66, Issue 5, 2010, page no. 234- 237.

31. Shukla A., Jat A.K., Sharma P. and Patel Y., Development and validation of a headspace gas chromatographic method for the determination of residual solvents in levetiracetam (API), International Journal of Pharmaceutical Science and Research, Vol 2, Issue 5, 2013, Page no. 1270-1275. 